\title{
STRUCTURAL RELIABILITY ASSESSMENT OF OFFSHORE WIND TURBINE JACKET CONSIDERING CORROSION DEGRADATION
}

\author{
Chao REN ${ }^{1}$, Younes AOUES ${ }^{2}$, Didier LEMOSSE ${ }^{3}$ AND Eduardo SOUZA DE CURSI ${ }^{4}$ \\ ${ }^{1}$ INSA Rouen Normandie \\ 76800 Saint-Étienne-du-Rouvray \\ chao.ren@insa-rouen.fr \\ 2 INSA Rouen Normandie \\ 76800 Saint-Étienne-du-Rouvray \\ younes.aoues@insa-rouen.fr \\ ${ }^{3}$ INSA Rouen Normandie \\ 76800 Saint-Étienne-du-Rouvray \\ didier.lemosse@insa-rouen.fr \\ ${ }^{4}$ INSA Rouen Normandie \\ 76800 Saint-Étienne-du-Rouvray \\ eduardo.souza@insa-rouen.fr
}

Key words: Reliability analysis, Corrosion degradation, Offshore jacket foundation, Surrogate model

\begin{abstract}
In this paper, an approach is proposed to conduct reliability analysis on an offshore jacket considering corrosion degradation under extreme load cases. Corrosion degradation is considered as thickness wastage of the jacket element, which is seen as time-dependent variables. One probabilistic corrosion in literature is adopted by using different distribution models. Also, three different inspection cases (environmental conditions) of the corrosion are studied. The reliability assessment is evaluated by Crude Monte Carlo simulation based on the trained surrogate model. Deep neural networks are used to train the surrogate model, because they are not limited by the distribution and dimension of variables. The results show that using different corrosion distribution model, the probabilities of failure of the jacket are different, even though they have the same mean and standard deviation values. In addition, with same assumption of the distribution model in corrosion, the reliability of the jacket changes a lot concerning different inspection cases. Furthermore, it is noted that the inspection cases have more influences on the reliability analysis of jacket than different corrosion distribution assumptions. At the end, two recommendations are derived from this work.
\end{abstract}

\section{INTRODUCTION}

In the last decade, wind energy is considered one the strong competitors of the conventional fossil fuels, due to the technology improvements. The role of wind energy in renewable energy utilization is becoming more and more important. Compared to land-based wind energy, there is more space and more stable and higher wind speed for offshore wind energy. More and more offshore wind turbines are currently 
under construction or planned. These offshore wind turbines has been installed in deep water. Steel jacket structures have been the main support structures, due to their higher stiffness at the footprint and the smaller surface facing ocean loads compared to the monopiles.

Many studies have been conducted with steel jacket structures. The long-term fatigue of offshore jacket is investigated in [1]. The fatigue of the jacket under three different load cases is evaluated. Ultimate strength assessment of offshore jacket can be found in [2]. However, the corrosion effect is not included in the above works. Corrosion can result in the reduction of member thickness and lead to the failure of the jacket structure. In [3], it proposes a framework to assess the corrosion effect on the offshore jacket. The jacket structures with corrosion effect under seismic loads is studied in [4]. Also, the time-dependent reliability assessment of the offshore jacket is investigated in [5] considering jacket shear capacity. In [6], the fatigue of offshore jacket with a simple corrosion model is studied. While, the jacket with corrosion effect under extreme load cases have not yet been considered. Moreover, multi-physics simulation models (aerodynamics, fluid-structure interaction, corrosion degradation, etc.) are involved in offshore wind jacket simulation and that makes the reliability analysis difficult. The reliability assessment based on Monte Carlo simulation (MCS) is much time-consuming and the use of approximation methods like (FORM/SORM) is also difficult, where these methods are gradient-based and the gradients of responses are difficult to evaluate. Hence, the first solution to deal with this is to substitute the numerical model with a metamodel, which is easier to estimate. There are many approaches like Kriging [7] and PCE [8] but they are limited by the distribution or dimension of random variables. Therefore, deep neural networks (DNN) are applied in this work, which have a good ability to conduct reliability assessment

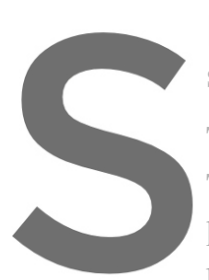
$[9,10]$. Thus, the reliab studied in this paper based The overview of the proposed approach is showed in The green part is to train hypercube sampling (LHS
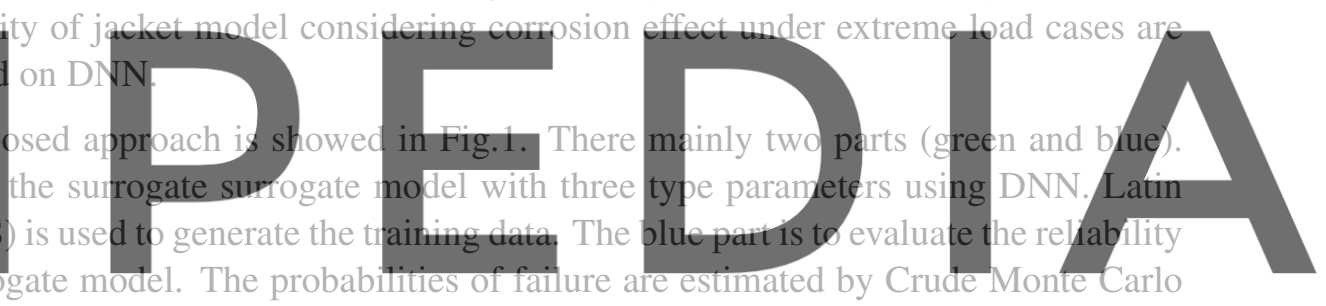

based on the trained surrogate model. The probabilities of failure are estimated by Crude Monte Carlo
simulation. In addition, the jacket model used in this study is referenced in Offshore Code Comparison

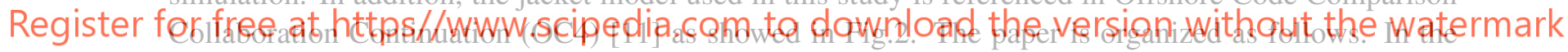

section 2, the corrosion model and multi-layer perception are introduced. The design load case, loads on

the jacket and limit state function are given in the section 3. The parameters selected for metamodel and the results of training surrogate model are in the section 4 . The reliability analysis results are listed in the section 5. Conclusions and recommendations are given in the section 6.

\section{MULTI-LAYER PERCEPTION AND CORROSION MODEL}

\subsection{Multi-layer perception}

The multi-layer perception (MLP) is one common type structure in deep neural networks. The basic structure is showed in the Fig.4. It is composed of three or more layers of neurons. The neurons of the neighboring layers are connected by weights and the output of each neuron is as follows:

$$
H_{i}^{(l)}=f\left(\sum_{j=1}^{n} w_{i j}^{(l)} H_{j}^{(l-1)}+b_{i}^{(l)}\right)
$$




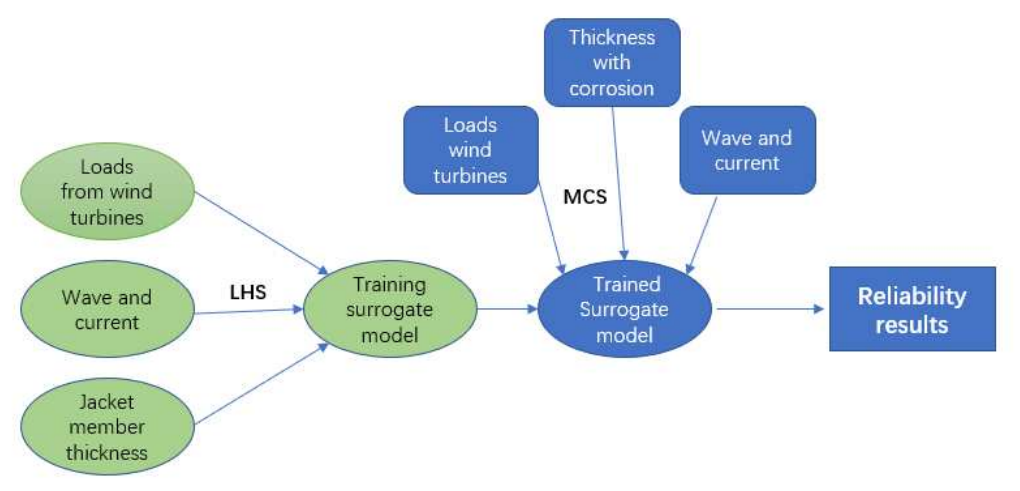

Figure 1: Overview of reliability assessment of the jacket
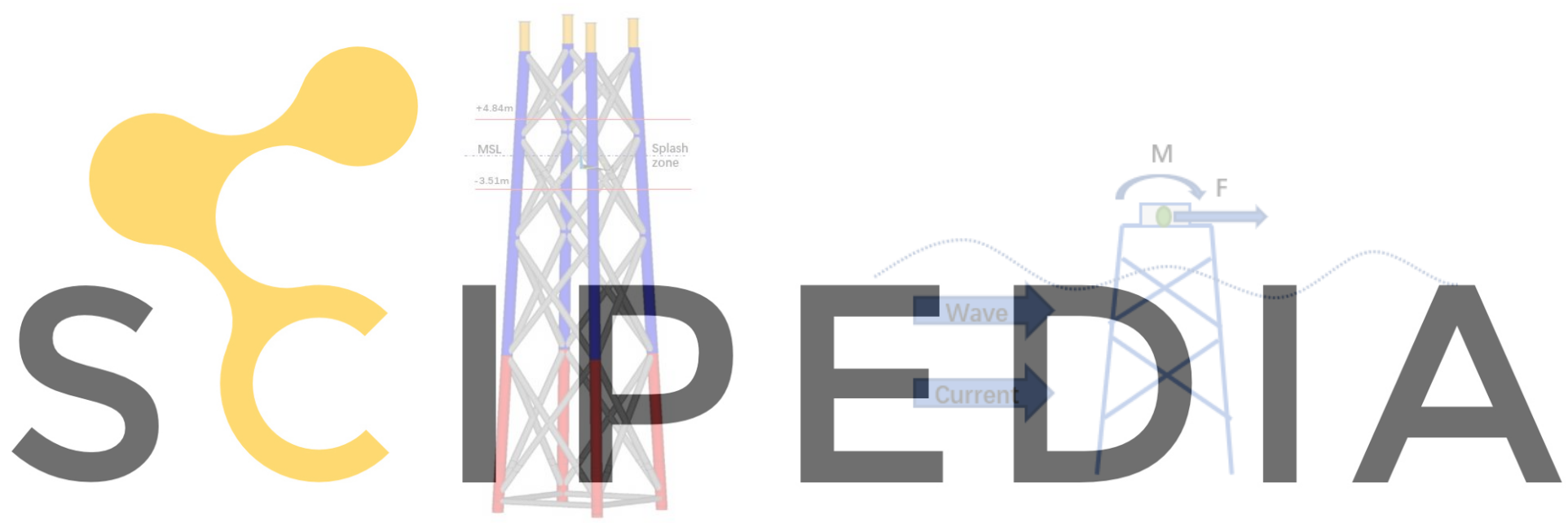

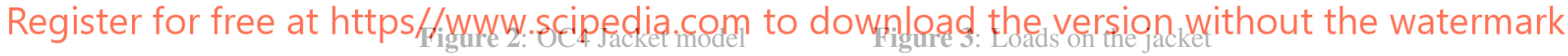

where $H_{i}^{(l)}$ is the output of the $i$ th neuron of the $l$ th layer, $w_{i j}^{(l)}$ are the weights of the $j$ th input, $b_{i}^{(l)}$ is the bias, $n$ is the number of the neurons of the $(l-1)$ th layer, and $f()$ is the activation function. In this paper, MLP trains the surrogate model using back propagation algorithm and the square errors are used as the loss function. As for the activation function in hidden layers, the solver, the neurons in hidden layers and the number of hidden layers, they are optimized by using hyperparameter optimization tools [12].

\subsection{Corrosion model}

In this work, the uniform corrosion is considered, which is most common form of corrosion and is uniformly distributed on the surface. The uniform corrosion can be simulated with a good approximation by a nonlinear function according to the studies $[13,14,15]$. The nonlinear function can be defined as following:

$$
W(t)=A\left(t-t_{p t}\right)^{B}
$$




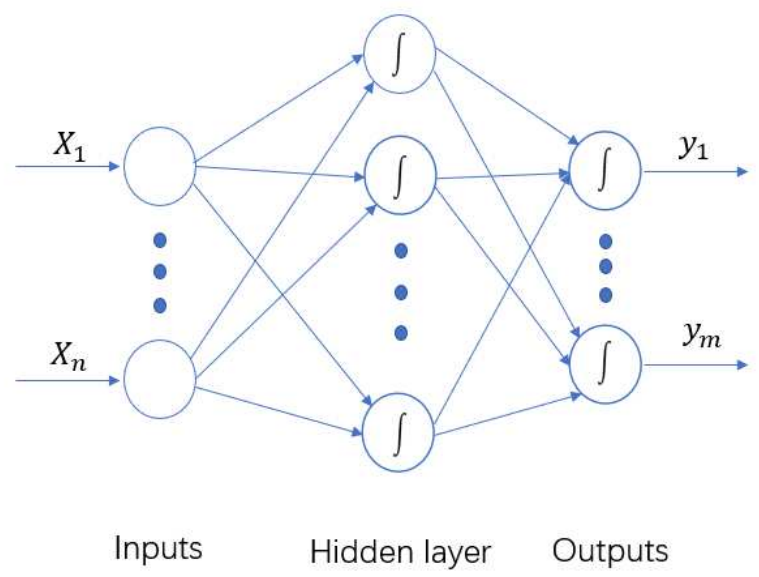

Figure 4: Multi-layer perception structures

where $W(t)$ is the thickness wastage in millimetres, $t$ is the lifetime and $t_{p t}$ is the corrosion protection time in years. A and B are two parameters that depend on the marine and environmental conditions. Our focus is mainly on the time after corrosion protection. Therefore, the protection time is ignored in this study. Additionally, the standard deviation of the thickness wastage is given by [15, 16].
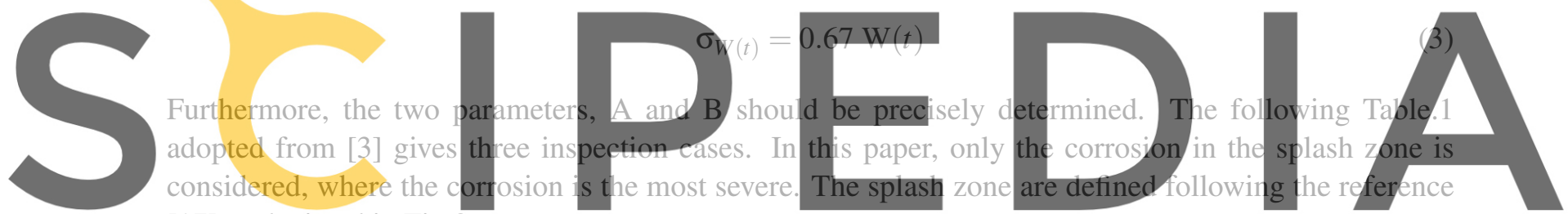

[17] as depicted in Fig.2

Register for free at https//www_scipedia.com to download the version without the watermark

\begin{tabular}{|l|l|l|}
\hline \multirow{2}{*}{\multicolumn{1}{|c|}{ Inspection case (IC) }} & \multicolumn{2}{|c|}{ Splash zone area } \\
\cline { 2 - 3 } & $\mathrm{A}(\mathrm{mm})$ & $\mathrm{B}$ \\
\hline 1. Not performed & 0.3 & 1 \\
\hline 2. Severe corrosion & 0.3 & 0.823 \\
\hline 3. No significant corrosion & 0.252 & 0.823 \\
\hline
\end{tabular}

\section{DESIGN LOAD CASES, LOADS AND LIMIT STATE FUNCTION}

\subsection{Design load cases}

In the standard codes IEC 61400-3 [18], 32 DLCs (design load cases) are defined covering various operational modes of the turbine such as normal operation, shut down and 50-years extreme conditions. They can be mainly categorized into two major groups namely ultimate and fatigue DLCs. Basically, the typical load cases applied in structural design of OWT is the fatigue load under normal sea conditions and the ultimate load under 50-year extreme condition [19]. All the DLCs should be carefully considered in 
design of the jacket. While, in this paper, our focus is mainly on the ultimate DLCs. The 50-year return period is generally considered as a critical ultimate load case as showed in Table.2, which is mostly considered to correspond to the parked turbine, under the 50-year EWM (extreme wind model) with a 50-years RWH (reduced wave height) and ECM (extreme current model) as described in DLC6.1b IEC 61400-3 [18].

Table 2: Design load case

\begin{tabular}{|l|l|l|}
\hline Load cases & Wind condition & Wave conditions \\
\hline Ultimate load case & EWM: $V_{g 50}$ & RWH: $1.32 * H_{s 50}$ \\
DLC.6.1b & ECM: $V_{c, e x}$ \\
\hline
\end{tabular}

\subsection{Loads}

OWT jacket support structures are generally exposed to complex and variable loads. These loads can roughly categorized into two groups as illustrated in Fig.3. The loads applied on the top of jacket are from wind turbine including aerodynamic loads and inertia / gravitational loads. The others are the hydrodynamic loads including the wave and current loads. The details are listed in the following subsection.

\subsubsection{Loads from wind turbine}

The loads from wind turbine mainly consist of aerodynamic and inertia loads. Aerodynamic loads are transferred from the rotor. The above loads are among of the support structure. [21]. In this study, the (Wind Partnership for Table.3.
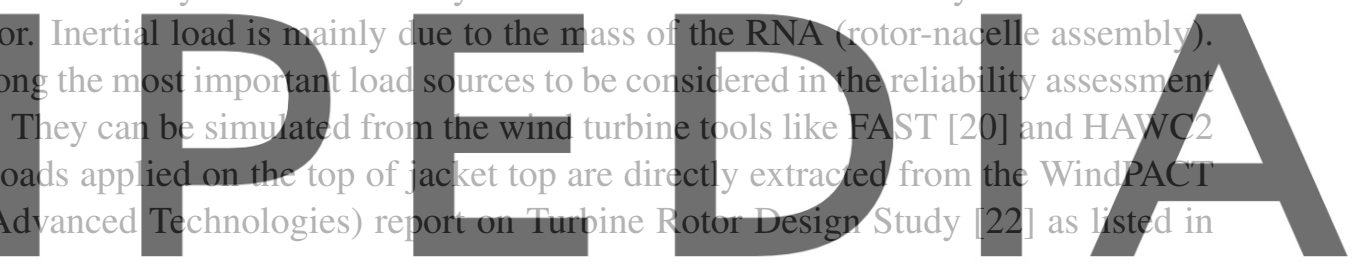

Register for free at https//www.scipediaocomptioddowndpadhthewersion without the watermark

\begin{tabular}{|l|l|l|l|}
\hline Load case & Thrust force $(\mathrm{kN})$ & Inertia/gravitional force $(\mathrm{kN})$ & Bending moment(kN-m) \\
\hline Ultimate load case & 12440 & 1928 & 223500 \\
\hline
\end{tabular}

\subsubsection{Hydrodynamic loads}

Hydrodynamic loads mainly consist of wave and current loads. It is critical to properly estimate the wave load, because waves will cause a significant force on the jacket. The choice of wave theory to apply to the model depends on the site characteristics. The decision of wave theory is also dependent on the ratio of the height to diameter of the structural member. When the diameter of the structure is less than one fifth of the wave length, Morrison's equation can be applied for the wave force estimation [23]:

$$
F_{\text {wave }}(z)=\frac{1}{4} \rho_{w} \pi D^{2} C_{M} \dot{u}(z, t)+\frac{1}{2} \rho_{w} D C_{D} u(z, t)|u(z, t)|
$$

where $D$ and $\rho_{w}$ are the diameter of jacket members and the density of the water with a typical value of $1025 \mathrm{~kg} / \mathrm{m}^{3}, C_{M}$ and $C_{D}$ are the coefficient of inertia and drag of the jacket members respectively, and 
their corresponding values are 1.6 and 1.0 respectively, according to [24]. $\dot{u}(z, t)$ and $u(z, t)$ are respectively horizontal acceleration and velocity of water particles, which can be obtained from linear/Airy wave theory. $z$ and $t$ are respectively the reference depth and time.

Current can induce a drag load acting on the jacket structure. The current velocity can be estimated using an exponential profile as follows [18]:

$$
u_{c}(z)=u_{M S L}\left(\frac{d+z}{d}\right)^{\frac{1}{7}}
$$

where $u_{M S L}$ is the current velocity at mean sea level (MSL), $d$ is the depth of water and $z$ is the reference depth. Usually, for simplicity, the direction of current and wave are assumed to be aligned. In this paper, both wave and current loads are defined in ANSYS ocean loading module [25] by giving the related wave and current parameters such as wave height, wave period and current velocity at MSL.

\subsection{Limit state function}

As mentioned above, this work focuses on the ultimate load case. Hence, only ultimate limit state is considered in this paper. The performance function of the ultimate state based on the Vons-Mises stress is given by:
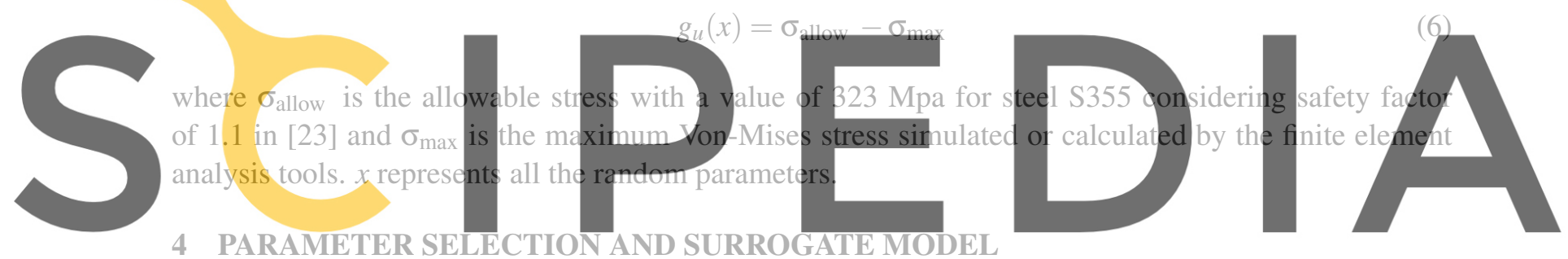

\section{Register fop frearaln}

For the random parameters, there are mainly three types as showed in the Table.4. The first is the loads $(F x, F z, M y)$ from the wind turbines. The second is the wave $(H s, T p)$ and current parameters $\left(C_{m s l}\right)$. The third type is the thickness parameters $\left(T_{\text {grey }}, T_{\text {blue }}\right)$ of jacket members. Here, the mean values of wave and current parameters in 50-year return period are referenced in [17]. The loads from wind turbines and wave and current parameters are assumed to follow normal distribution with standard deviation equal to $10 \%$ of their mean values as done in [26]. As for the thickness parameters $T_{\text {grey }}$ and $T_{\text {blue }}$, they represents respectively the thickness of braces in splash zone with grey color and the thickness of legs in splash zone with blue color as showed in Fig.2. Here, the thickness of members are considered as random variables instead of the corrosion wastage, because different corrosion distributions will be considered. In addition, the original thickness of braces and legs in the splash zone are $20 \mathrm{~mm}$ and $35 \mathrm{~mm}$. Corrosion degradation will cause the thickness wastage of jacket members. Therefore, for training the surrogate model process, it is better to assume that the thickness parameters follow the uniform distribution with lower bound (open interval) equal to 0 and upper bound equal to original thickness. In this case, the trained surrogate model may have good capacity to predict the corrosion effect. 
Chao et al.

Table 4: Stochastic parameters in reliability assessment

\begin{tabular}{|l|l|l|l|}
\hline Stochastic variables & $\begin{array}{l}\text { Mean } \\
\text { (Lower bound) }\end{array}$ & $\begin{array}{l}\text { Standard deviation } \\
\text { (Upper bound) }\end{array}$ & Distribution \\
\hline$F x$-Thrust force $(k N)$ & 12440 & 1244 & Normal \\
\hline$F z$-Inertia force $(k N)$ & 1928 & 192.8 & Normal \\
\hline$M y$-Bending moment $(k N * m)$ & 223500 & 22350 & Normal \\
\hline$H s$-Wave height $(m)$ & 10.34 & 1.034 & Normal \\
\hline$T p$-Wave period $(s)$ & 10.87 & 1.087 & Normal \\
\hline$C_{m s l}$-Current velocity $(\mathrm{m} / \mathrm{s})$ & 1.2 & 0.12 & Normal \\
\hline$T_{\text {grey }}$-Thickness of braces $(\mathrm{mm})$ & 0 & 20 & Uniform \\
\hline$T_{\text {blue }}$-Thickness of legs $(\mathrm{mm})$ & 0 & 35 & Uniform \\
\hline
\end{tabular}

\subsection{Surrogate model}

For training process with MLP, all the parameters as listed in Table.4 are considered as inputs and the maximum stress in static analysis simulated by ANSYS is the output. Moreover, one criterion is used to evaluate the surrogate model. That is the mean absolute percentage error (MAPE), given by:

$$
\text { MAPE }=\frac{1}{n} \sum_{i=1}^{i=n}\left|\frac{y_{i}-\widehat{y}_{i}}{y_{i}}\right| * 100 \%
$$

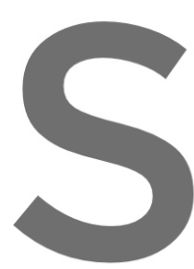

where $y_{i}$ and $\widehat{y_{i}}$ are the actu
process is by increasing tr.
in this paper). In this stud
number of test data equals
1000 simulations) are used
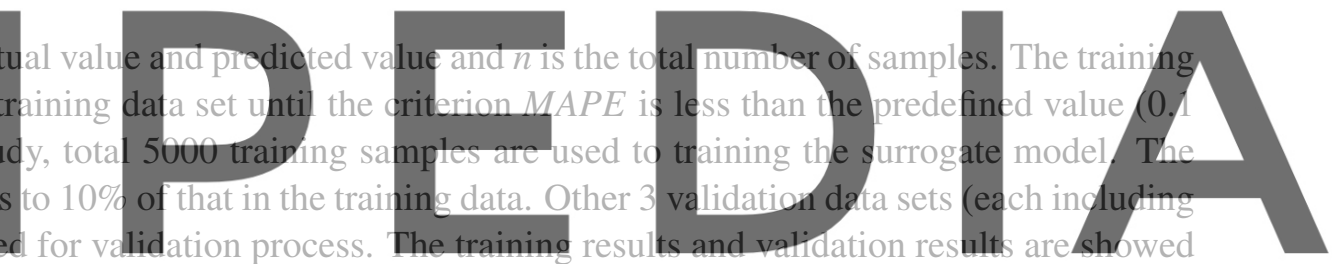

in Table.5. The predicted values and true values of test data set and validation data set 1 are plotted in

Register fbirffree at https//www.scipedia.com to download the version without the watermark

Table 5: Surrogate model training results

\begin{tabular}{|c|c|c|c|c|c|}
\hline $\begin{array}{l}\text { Validation data } \\
\text { set }\end{array}$ & $\begin{array}{l}\text { Traning data } \\
\text { MAPE }(\%)\end{array}$ & $\begin{array}{l}\text { Test data } \\
\text { MAPE (\%) }\end{array}$ & $\begin{array}{l}\text { Validation data } \\
\text { MAPE }(\%)\end{array}$ & Pf_pre & Pf_actual \\
\hline 1 & \multirow{3}{*}{0.0261} & \multirow{3}{*}{0.025} & 0.0443 & 0.017 & 0.017 \\
\hline 2 & & & 0.0428 & 0.001 & 0.001 \\
\hline 3 & & & 0.0253 & 0.103 & 0.103 \\
\hline
\end{tabular}

As showed in Table.5 and Fig.5, the trained surrogate model achieve to predict the unknown validation data set. All the MAPEs of three validation data sets are less $0.1 \%$. Also, the predicted probabilities ( $\mathrm{Pf}_{\text {_pre }}$ ) of failure of validation data sets are equal to the true probabilities ( $\mathrm{Pf}_{-}$actual) of failure of validation data sets. 


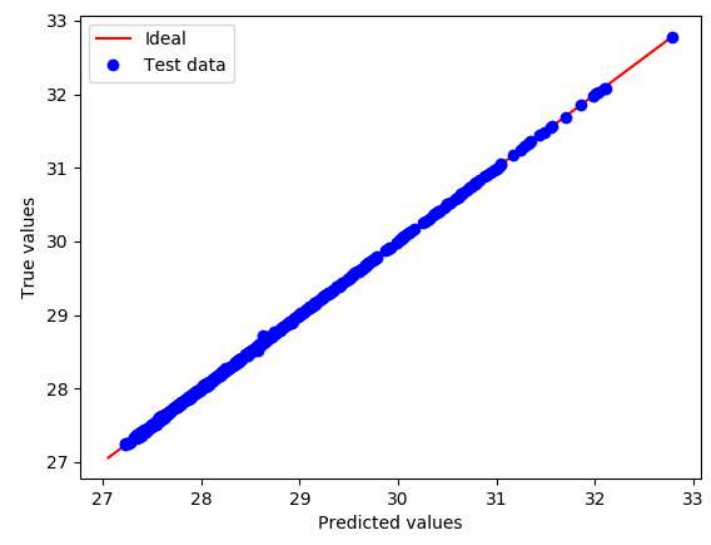

(a) Test data

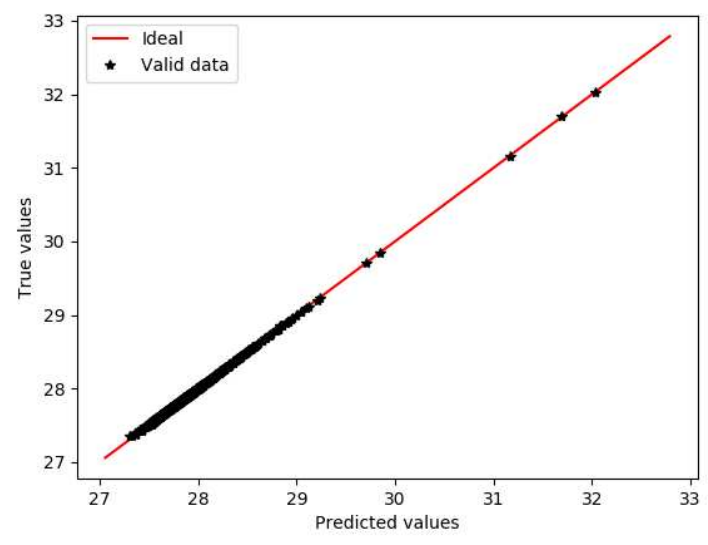

(b) Validation data set 1

Figure 5: Comparison results between predicted values and true values

\section{RESULTS AND COMPARISONS}

The design life of the OC4 jacket is about 20 years. The 20 years are divided into 20 time nodes with each interval equal to one year. A reliability analysis is performed each year. Due to a lack of corrosion measurement, two probabilistic corrosion models are considered, Gamma and Lognormal distributions respectively. For these twi shown in Table.1. Addition To evaluate reliability df each inspection case $(\mathbb{I C})$ stresses of jacket are estimated by the trained surro
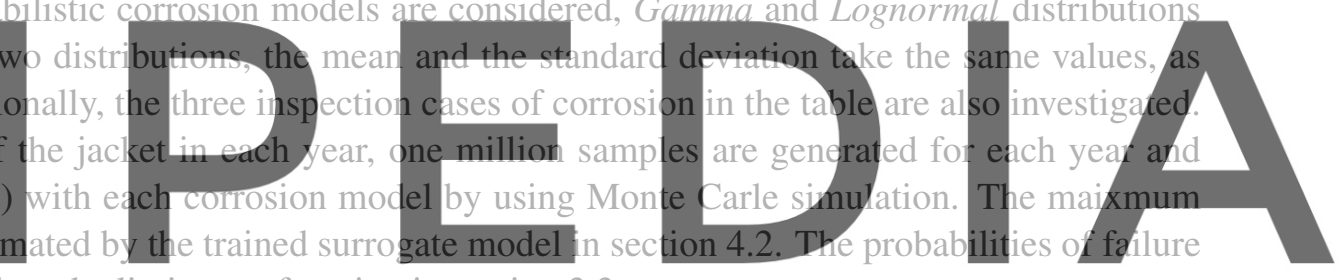

(Pfs) are evaluated based on the limit state function in section 3.3.

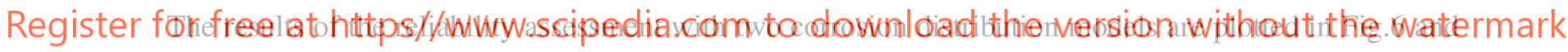

Fig.7. It is clear that inspection cases (environmental conditions) have great influence on the reliabil-

ity assessment of the jacket. At the first 6 years, the inspection cases seems to have little influence on the reliability of the jacket. While, after the 6th year, the differences of Pfs with different inspection cases appear. In addition, the results of the two corrosion models are compared in Fig.8. It is noted that the probabilities of failure at the end of 20 years in two corrosion model are different in all the three inspection cases. In IC1, at the beginning, the probabilities of failure of the jacket are higher with the Lognormal distribution assumption of corrosion. However, after the 13th year, the probabilities of failure with Gamma distribution model are greater. In IC2 and IC3, the jacket model with corrosion assumption of Lognomal distribution always has bigger probabilities of failure but the differences between two corrosion distributions are not obvious compared with IC1. Meanwhile, it should be mentioned that the differences in different inspection cases have more effects on the reliability assessment of jacket, compared to different corrosion distribution assumptions as showed in Fig.8. At last, the 20th year probabilities of failure of the jacket in two corrosion models with three inspection cases are given in Table.6. The corresponding coefficient of variations and $95 \%$ confidence interval are also listed in the table. All the probabilities of failure in the 20th year are greater than the design probability of failure $0.01 \%$ [23]. 


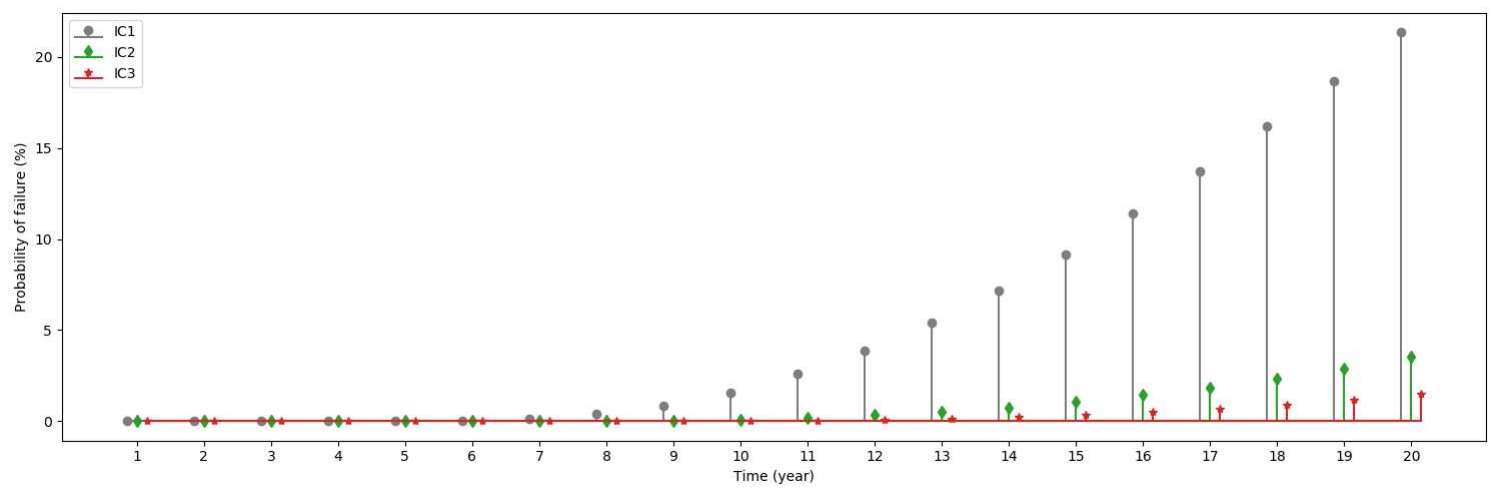

Figure 6: Reliability results with Gamma distribution corrosion model

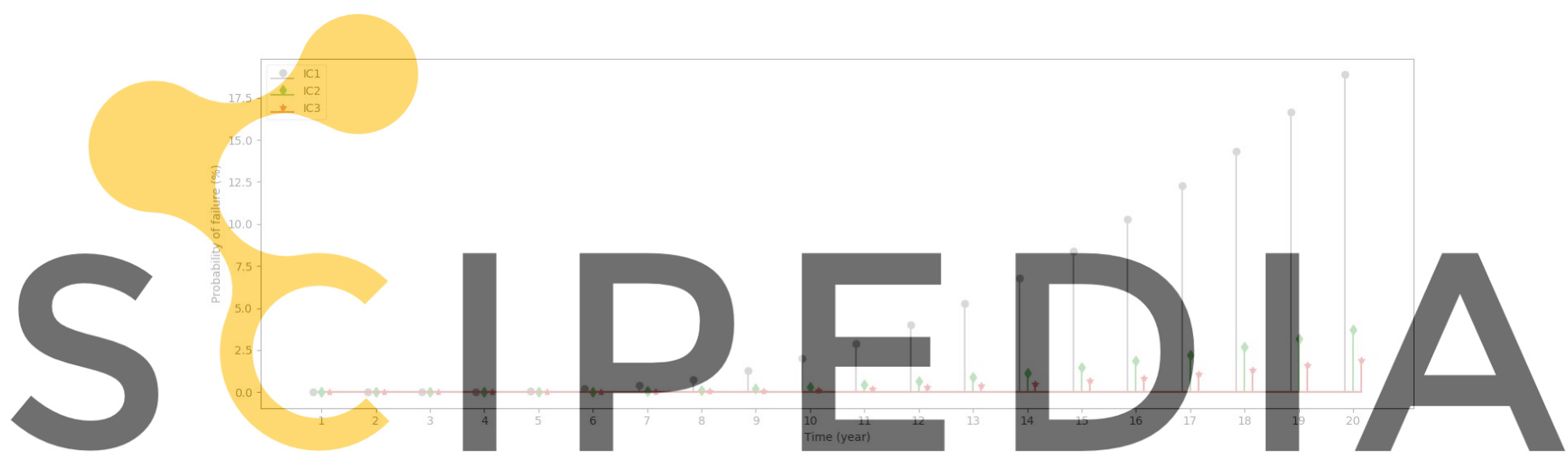

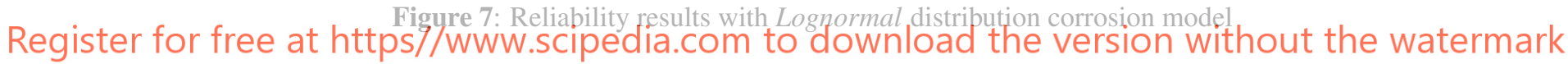

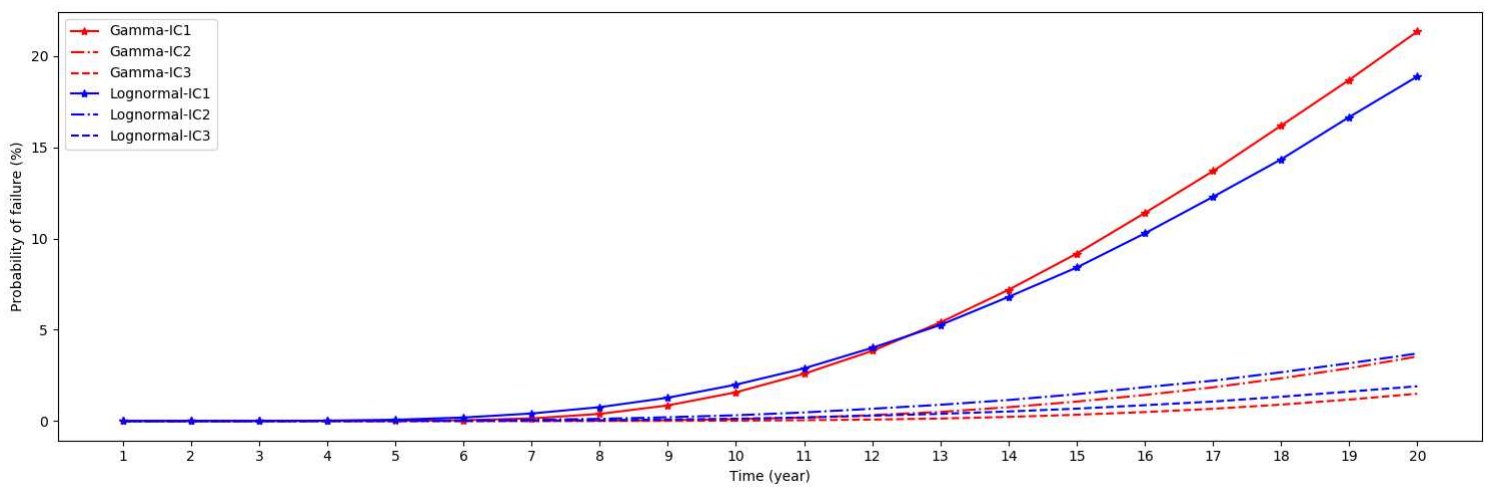

Figure 8: Comparison of reliability assessment results in two corrosion models 
Table 6: Probabilities of failure in the 20th year with two corrosion models

\begin{tabular}{|l|l|l|l|}
\hline $\begin{array}{l}\text { Gamma distribution } \\
\text { Inspection case(IC) }\end{array}$ & $\begin{array}{l}\text { Pf in the 20th } \\
\text { year }(\%)\end{array}$ & $\begin{array}{l}\text { Coefficient of } \\
\text { variation }(\%)\end{array}$ & $\begin{array}{l}\text { 95\% confidence interval } \\
\text { of Pf }(\%)\end{array}$ \\
\hline IC1 & 21.37 & 0.19 & {$[21.29,21.45]$} \\
\hline IC2 & 3.54 & 0.52 & {$[3.50,3.58]$} \\
\hline IC3 & 1.49 & 0.81 & {$[1.47,1.51]$} \\
\hline $\begin{array}{l}\text { Lognormal distribution } \\
\text { Inspection case(IC) }\end{array}$ & $\begin{array}{l}\text { Pf in the 20th } \\
\text { year }(\%)\end{array}$ & $\begin{array}{l}\text { Coefficient of } \\
\text { variation }(\%)\end{array}$ & $\begin{array}{l}95 \% \text { confidence interval } \\
\text { of Pf }(\%)\end{array}$ \\
\hline IC1 & 18.88 & 0.21 & {$[18.80,18.96]$} \\
\hline IC2 & 3.71 & 0.51 & {$[3.67,3.75]$} \\
\hline IC3 & 1.89 & 0.72 & {$[1.86,1.92]$} \\
\hline
\end{tabular}

\section{CONCLUSIONS AND RECOMMENDATIONS}

In this paper, an approach is proposed to evaluate the reliability of failure of an OWT jacket considering corrosion degradation under extreme load cases. The reliability assessment is based on a surrogate model trained by deep neurons networks. The corrosion degradation is considered as time-dependant variables. The probabilistic corrosion model is adopted in this paper by using two probability distribution of the corrosion parameters, Lognormal and Gamma respectively. In addition, three inspection cases of corrosion are investigated. The results show that:

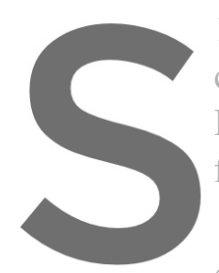
1. The probabilities of failure of the jacket are slightiy the same for severe corrosion and no significant
corrosion when the contosion parameters gre assumed Lognormal and Gammo probability distribution.
However, when the inspection case is not-performed and the corrosion is severe; then the probability of
failure is different regarding the gamma and lognormal distributions models.

2. With same assumption of corrosion distribution, the probabilities of failure of jacket will depend

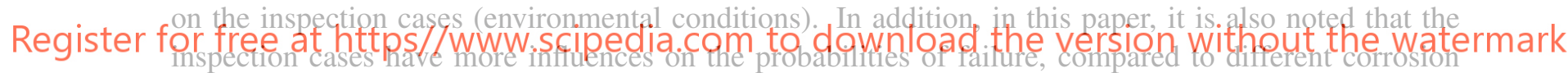
distribution assumptions (Gamma and Lognormal distribution in this paper).

3. With two corrosion distributions studied in this work, it is found that the probabilities of failure in the end of 20 years can reach up to $21.37 \%$ for the maximum value and $1.49 \%$ for the minimum value. More importantly, all the probabilities in the two corrosion distributions with three inspection cases at the end of 20th year are greater than design probabilities of failure $0.01 \%$ in [23].

From this work, two recommendations are proposed. Firstly, the extreme load cases with corrosion degradation should be considered in design of the offshore jacket, in the view of the effect of corrosion and the increase extreme weather conditions in recent years. Secondly, the corrosion model should be chosen carefully, if on-site corrosion data is not available or not sufficient to estimate the future corrosion. 


\section{ACKNOWLEDGE}

Financial support for this work was provided by the CSC program (China Scholarship Council) between the People's Republic of China and the INSA group. This support is gratefully acknowledge.

\section{REFERENCES}

[1] Wenbin Dong, Torgeir Moan, and Zhen Gao. Long-term fatigue analysis of multi-planar tubular joints for jacket-type offshore wind turbine in time domain. Engineering Structures, 33(6):20022014, 2011.

[2] B Yeter, Y Garbatov, and C Guedes Soares. Ultimate strength assessment of jacket offshore wind turbine support structures subjected to progressive bending loading. Ships and Offshore Structures, 14(2):165-175, 2019.

[3] Ashish Aeran, Sudath C Siriwardane, Ove Mikkelsen, and Ivar Langen. A framework to assess structural integrity of ageing offshore jacket structures for life extension. Marine Structures, 56:237-259, 2017.

[4] Yang Yang, Qingjin Wu, Zheng He, Ziyue Jia, and Xiaowei Zhang. Seismic collapse performance of jacket offshore platforms with time-variant zonal corrosion model. Applied Ocean Research, 84:268-278, 2019.

[5] Yong Bai, Hui-bin Yan, Yu Cao, Younghoon Kim, Yong-yan Yang, and Hua Jiang. Time-dependent reliability assessment of offshore jacket platforms. Ships and Offshore Structures, 11(6):591-602, 2016.

[6] Wenbin Dong, Torgeir Moan, and Zhen Gao. Fatigue reliability analysis of the jacket support structure for offshore wind turbine considering the effect of corrosion and inspection. Reliability Engineering \& System Safety, 106:11-27, 2012.

[7] Irfan Kaymaz. Application of kriging method to structural reliability problems. Structural Safety, 27(2):133-151, 2005.

[8] Roger G Ghanem and Pol D Spanos. Stochastic finite elements: a spectral approach. Courier Corporation, 2003.

[9] Jorge E Hurtado and Diego A Alvarez. Neural-network-based reliability analysis: a comparative study. Computer methods in applied mechanics and engineering, 191(1-2):113-132, 2001.

[10] AA Chojaczyk, AP Teixeira, Luís C Neves, JB Cardoso, and C Guedes Soares. Review and application of artificial neural networks models in reliability analysis of steel structures. Structural Safety, 52:78-89, 2015.

[11] Fabian Vorpahl, Wojciech Popko, and Daniel Kaufer. Description of a basic model of the "upwind reference jacket" for code comparison in the oc4 project under iea wind annex xxx. techreport, Fraunhofer IWES, 2011.

[12] F. Pedregosa, G. Varoquaux, A. Gramfort, V. Michel, B. Thirion, O. Grisel, M. Blondel, P. Prettenhofer, R. Weiss, V. Dubourg, J. Vanderplas, A. Passos, D. Cournapeau, M. Brucher, M. Perrot, and E. Duchesnay. Scikit-learn: Machine learning in Python. Journal of Machine Learning Research, 12:2825-2830, 2011. 
[13] S Feliu, Manuel Morcillo, and S Feliu Jr. The prediction of atmospheric corrosion from meteorological and pollution parameters-ii. long-term forecasts. Corrosion Science, 34(3):415-422, 1993.

[14] Jeom Kee Paik, Sung Kyu Kim, and Sang Kon Lee. Probabilistic corrosion rate estimation model for longitudinal strength members of bulk carriers. Ocean Engineering, 25(10):837-860, 1998.

[15] Robert E Melchers. Corrosion uncertainty modelling for steel structures. Journal of Constructional Steel Research, 52(1):3-19, 1999.

[16] Robert E Melchers et al. Probabilistic modelling of marine corrosion of steel specimens. In The Fifth International Offshore and Polar Engineering Conference. International Society of Offshore and Polar Engineers, 1995.

[17] T Fischer, W De Vries, and B Schmidt. Upwind design basis. Upwind deliverable (WP4: Offshore foundations and support structures), Endowed Chair of Wind Energy (SWE) at the Institute of Aircraft Design Universit at Stuttgart, 2010.

[18] IEC IEC. 61400-3, wind turbines-part 3: Design requirements for offshore wind turbines. International Electrotechnical Commission, Geneva, 2009.

[19] Theo Gentils, Lin Wang, and Athanasios Kolios. Integrated structural optimisation of offshore wind turbine support structures based on finite element analysis and genetic algorithm. Applied energy, 199:187-204, 2017.

[20] Pamela P Walatka, Jean Clucas, R Kevin McCabe, Todd Plessel, Rick Potter, and DM Cooper. Fast user guide. 1994.

[21] Torben Juul Larsen and Anders Melchior Hansen. How 2 hawc2, the user's manual. target, 2(2), 2007.

[22] Michael W LaNier. Lwst phase i project conceptual design study: Evaluation of design and construction approaches for economical hybrid steel/concrete wind turbine towers; june 28, 2002-july 31, 2004. Technical report, National Renewable Energy Lab., Golden, CO (US), 2005.

[23] Det Norske Veritas. Dnv-os-j101-design of offshore wind turbine structures. Det Norske Veritas, 2004.

[24] GL Dnv. Dnvgl-st-0126: Support structures for wind turbines. Oslo, Norway: DNV GL, 2016.

[25] Release ANSYS. 18.0 user's guide. 2017.

[26] RO Ivanhoe, L Wang, and A Kolios. Generic framework for reliability assessment of offshore wind turbine jacket support structures under stochastic and time dependent variables. Ocean Engineering, 216:107691, 2020. 